\begin{tabular}{|c|c|c|}
\hline Case Reports in & \multicolumn{2}{|c|}{ Case Rep Gastroenterol 2019;13:165-172 } \\
\hline Gastroenterology & $\begin{array}{l}\text { DOI: } 10.1159 / 000499447 \\
\text { Published online: April 9, } 2019\end{array}$ & $\begin{array}{l}\text { (c) } 2019 \text { The Author(s) } \\
\text { Published by S. Karger AG, Basel } \\
\text { www.karger.com/crg }\end{array}$ \\
\hline & $\begin{array}{l}\text { This article is licensed under } \\
\text { International License (CC BY- } \\
\text { Usage and distribution for com }\end{array}$ & $\begin{array}{l}\text { nons Attribution-NonCommercial } 4.0 \\
\text { ger.com/Services/OpenAccessLicense). } \\
\text { uires written permission. }\end{array}$ \\
\hline
\end{tabular}

\title{
Early Gastric Adenosquamous Carcinoma Resected Using Endoscopic Submucosal Dissection
}

\author{
Han-lk Bae An Na Seo \\ Department of Pathology, School of Medicine, Kyungpook National University, \\ Kyungpook National University Chilgok Hospital, Daegu, South Korea
}

\section{Keywords}

Gastric cancer · Adenosquamous carcinoma · Endoscopic submucosal dissection

\begin{abstract}
Adenosquamous carcinoma (ASC) is characterized as a mixed neoplasia (adenocarcinoma with glandular architecture and squamous cell carcinoma [SqCC]). Because most ASCs are found in the advanced stage at the time of diagnosis, early gastric ASC is an extremely rare tumor. Here, we present the case of an incidental finding of early gastric ASC in a 61-year-old Korean man during a health screening. Histological biopsy through esophagogastroduodenoscopy revealed a moderately differentiated adenocarcinoma in the distal body. The patient underwent endoscopic submucosal dissection and was diagnosed with ASC. The SqCC components of this tumor were located adjacent to the adenocarcinoma components and occupied $40 \%$ of the tumor. Two individual tumor components had invaded into the submucosal layer with lymphovascular invasion. An abdominal computed tomography scan indicated no definite mass or wall thickening of the stomach and revealed neither lymph node enlargement nor distant metastasis. To the best of our knowledge, this is the 14th reported case of early gastric ASC, and all cases were reported in East Asians.




\section{Case Reports in Gastroenterology}

Case Rep Gastroenterol 2019;13:165-172

DOI: 10.1159/000499447

c) 2019 The Author(s). Published by S. Karger AG, Basel www.karger.com/crg

Bae and Seo: Early Gastric Adenosquamous Carcinoma Resected Using Endoscopic Submucosal Dissection

\section{Introduction}

Gastric cancer is one of the most fatal malignancies worldwide despite recent advances in screening, techniques, and regimens. Adenocarcinoma is the most common histologic subtype of primary gastric cancer, whereas adenosquamous carcinoma (ASC) is an extremely rare subtype, accounting for approximately $1 \%$ of all gastric cancers $[1,2]$. ASC has been shown to have an aggressive behavior with advanced stage at diagnosis, as well as synchronous and metachronous lymph node and/or liver metastases [1,2]. Meanwhile, very few cases of early ASC extending to the mucosa and/or submucosa have been reported; therefore, clinical behavior of and treatment strategy for early ASC remain unclear. Herein, we report a probable 14th case of early ASC in the anterior wall of the distal body of the stomach in a 61-year-old man, along with a review of previous cases published in the English literature.

\section{Case Presentation}

A 61-year-old Korean man who was incidentally diagnosed with suspected adenocarcinoma in his health screening test was referred to the gastroenterology unit of our institution. Although the patient had diabetes mellitus and variant angina, he had been treated with standard medication, and he had been relatively healthy until recently. He had also no significant symptoms, such as weight loss, abdominal pain, poor oral intake, and abdominal discomfort. Physical examination showed no signs of fever, chills, diarrhea, and abnormal bowel movements or sound. Preliminary laboratory test results were within normal limits, but the liver function test showed mild elevated levels: aspartate aminotransferase, $40 \mathrm{U} / \mathrm{L}$; alanine aminotransferase, $72 \mathrm{U} / \mathrm{L}$; and gamma glutamyl transpeptidase, $54 \mathrm{U} / \mathrm{L}$. Esophagogastroduodenoscopy revealed a mucosal erosive lesion with a well-visible underlying vascular pattern, suggestive of type 0 -IIc early gastric cancer at the anterior wall of the distal body of the stomach (Fig. 1a). Histopathologic examination of the endoscopic biopsy specimen showed moderately differentiated adenocarcinoma. The results of the Helicobacter pylori urease test (Campylobacter-like organism test; HALYARD Health, Yokohama, Japan) were negative. An abdominal computed tomography scan indicated no definite mass or wall thickening of the stomach and revealed neither lymph node enlargement nor distant metastasis (Fig. 1b). Subsequently, the patient underwent endoscopic submucosal dissection (ESD) and achieved en bloc resection with negative margins (Fig. 1c). The resected gastric ESD specimen was carefully examined by serial sections at 2-mm intervals and produced mapping. Microscopically, the tumor, measuring $1.6 \times 0.8 \mathrm{~cm}$, comprised both $60 \%$ adenocarcinoma and $40 \%$ squamous cell carcinoma (SqCC) components. Adenocarcinoma components showed irregular glandular structures with a tubular type and were moderately differentiated (Fig. 2a). The SqCC components were located adjacent to the adenocarcinoma components, and 2 individual lesions collided in the center of the tumor. The SqCC components exhibited a large solid nest of squamous cells with intercellular bridges and keratinization (Fig. 2b). Both individual components had invaded into the submucosal layer $(800 \mu \mathrm{m})($ Fig. $2 \mathrm{c}, \mathrm{d})$ accompanied with extensive lymphoid follicles. Lymphovascular invasion was also found (Fig. 2e). Notably, a few cells with mucin production were infrequently found within some areas of the SqCC component (Fig. 2f). As expected, immunohistochemistry (IHC) for $\mathrm{p} 40$ was positive in the SqCC components but negative in the adenocarcinoma components (Fig. 3a, b). In contrast, IHC for CK7 was negative in the SqCC components but positive in the adenocarcinoma components (Fig. 3c, d). Interestingly, IHC for carcinoembryonic antigen (CEA) was positive in some areas of both 


\section{Case Reports in Gastroenterology}

Case Rep Gastroenterol 2019;13:165-172

DOI: $10.1159 / 000499447$

(c) 2019 The Author(s). Published by S. Karger AG, Basel www.karger.com/crg

Bae and Seo: Early Gastric Adenosquamous Carcinoma Resected Using Endoscopic Submucosal Dissection

components (Fig. 3e, f). To identify molecular characteristics, microsatellite instability testing was performed by comparing the allelic profiles of the 5 microsatellite markers (BAT-26, BAT25, D5S346, D17S250, and D2S123) in formalin-fixed paraffin-embedded tumor and normal tissues. The polymerase chain reaction products were determined using a DNA autosequence (ABI 3500xL genetic analyzer; Applied Biosystems, Foster City, CA, USA) according to the instructions. The results of microsatellite instability testing were microsatellite stable in both the adenocarcinoma and SqCC components. In contrast, few tumor cells in the adenocarcinoma components were positive in the Epstein-Barr virus-encoded RNA in situ hybridization.

Additional gastrectomy was recommended for the patient, but the patient refused all procedures and treatments and was transferred to another hospital. Subsequently, the patient was lost to follow-up.

\section{Discussion}

Gastric ASC is characterized by the coexistence of 2 components (adenocarcinoma with variously differentiated grades and $\mathrm{SqCC}$ ) within the same tumor [2, 3]. Since its description in 1905 by Rolleston and Trevor [4], it was recognized as a separate entity based on the World Health Organization classification. Gastric ASC is an extremely aggressive tumor, and the majority of these tumors are found in an already advanced stage on initial diagnosis [2, 5]. Hence, gastric ASC is associated with a worse prognosis than conventional adenocarcinoma [2]. Feng et al. [2] demonstrated that $25.4 \%$ of patients with ASC had distant metastasis, and its most common location was the liver, followed by peritoneal dissemination. However, owing to the rarity of early ASC, important issues, such as clinicopathologic features, optimal treatment strategies, and prognosis, remain unclear. Since the first case of early ASC reported by Samejima et al. [6] in 1974, to the best of our knowledge, only 14 cases, including the present case, have been reported [7-11]. Notably, all cases were reported in East Asians, i.e., in 12 Japanese and 2 Korean patients. Unfortunately, we are unaware of any report of early ASC from the West. The reason for this might be early discovery through multiphasic health screening examinations in East Asians. In our case, the patient was asymptomatic, and the adenocarcinoma component was incidentally found in the biopsy of his health screening esophagogastroduodenoscopy. Early gastric ASC in the 14 reported cases was slightly more prevalent in men than in women (male to female ratio, 4:3), and the mean age was 66.9 years ( \pm standard deviation, 3.03 years). The most frequent location for its development was the lower third $(7 / 14,50 \%)$ of the stomach. Notably, of the 14 cases of early gastric ASC, 3 already had bulky synchronous distant metastasis, especially in the liver, at the time of diagnosis, although the tumor was limited to the submucosal layer [7-9]. The other case revealed multiple liver metastases 2 months after ESD [12]. In the light of these findings, early gastric ASC could also be aggressive and fatal even when found at an early stage.

The histogenesis of gastric ASC remains controversial. Several hypotheses have been proposed [1, 2, 9]: (1) squamous metaplastic transformation of an adenocarcinoma; (2) cancerization of heterotopic aberrant squamous epithelium; (3) oncogenic transformation of metaplastic nonneoplastic squamous cells; (4) endothelial cells of regional vessels differentiated toward squamous elements; (5) differentiation of multipotent stem cells of the gastric mucosa toward both squamous and glandular cells; and (6) collision of concurrent adenocarcinoma and SqCC. Currently, the first hypothesis is favored by many researches. As the basis of this hypothesis, (1) most of the SqCC components were located at an invasive deeper layer, 


\section{Case Reports in Gastroenterology}

Case Rep Gastroenterol 2019;13:165-172 DOI: 10.1159/000499447

(c) 2019 The Author(s). Published by S. Karger AG, Basel www.karger.com/crg

Bae and Seo: Early Gastric Adenosquamous Carcinoma Resected Using Endoscopic Submucosal Dissection

whereas the adenocarcinoma components were located in the mucosal layer [13]; (2) an obvious transition area exists between the 2 components and adjoined adenocarcinoma components [1]; and (3) positive expression of CK7 and CEA was found in SqCC components [1, 13]. For the accurate diagnosis of true ASC, confirmation of the presence of both individual components outside the cardia, without esophageal involvement and without ASC in other organs, is required. In the present case, the tumor existed in the distal body where ectopic squamous cells are seldom seen. In addition, SqCC components were located adjacent to the adenocarcinoma components, and they were found in both mucosal and submucosal layers but not just in the deepest invasive tumor front of adenocarcinoma. Interestingly, our case also infrequently showed few tumor cells with mucin production within some areas of the SqCC components. This lesion was considered as an abrupt transition from glandular epithelium to SqCC. Furthermore, CEA expression was positively detected in this lesion of SqCC components. In contrast, adenocarcinoma components showed positive expression for CK7, but SqCC components did not. Our findings can also be supported by the hypothesis of a squamous metaplastic transformation of an adenocarcinoma. With regard to the molecular characteristics of our case, the tumor was microsatellite stable, whereas few blue cells of positive Epstein-Barr virus were found in some areas of the adenocarcinoma components. Furthermore, a few tumor cells were positive for $\mathrm{p} 53$ in both SqCC and adenocarcinoma components. Unfortunately, we did not achieve a long clinical prognosis of our case. To the best of our knowledge, the identification of early ASC resected using ESD in Korea is the second case reported. Al-though more accumulating data are required, early gastric ASC could be clinically aggressive and fatal even when detected at an early stage.

In summary, we report an exceptionally rare case of early gastric ASC with invasion into the submucosa and lymphovascular invasion. Due to its rarity, there are no well-established treatment guidelines for patients with early ASC. Thus, centralized and collaborative largesample investigations are necessary to determine the risk of relapse, patient outcomes, and new optimal treatment approaches to achieve a better prognosis.

\section{Acknowledgement}

We are grateful to Seong Woo Jeon, MD, PhD, of Kyungpook National University Chilgok Hospital (Daegu, South Korea) for the generous help with the esophagogastroduodenoscopy and ESD.

\section{Statement of Ethics}

The authors have no ethical conflicts to disclose. This study was approved by the Institutional Review Board of Kyungpook National University Chilgok Hospital with a waiver of informed consent (IRB No. 2019-02-011).

\section{Disclosure Statement}

The authors have no conflicts of interest to declare. 
Bae and Seo: Early Gastric Adenosquamous Carcinoma Resected Using Endoscopic Submucosal Dissection

\section{Funding Sources}

There were no funding sources.

\section{Author Contributions}

Substantial contributions to the conception or design of the work: A.N.S. Acquisition, analysis, or interpretation of data for the work: H.-I.B. and A.N.S. Drafting the work or revising it critically for important intellectual content: H.-I.B. and A.N.S. Final approval of the version to be published: A.N.S.

\section{References}

1 Chen H, Shen C, Yin R, Yin Y, Chen J, Han L, et al. Clinicopathological characteristics, diagnosis, treatment, and outcomes of primary gastric adenosquamous carcinoma. World J Surg Oncol. 2015 Apr;13(1):136.

2 Feng F, Zheng G, Qi J, Xu G, Wang F, Wang Q, et al. Clinicopathological features and prognosis of gastric adenosquamous carcinoma. Sci Rep. 2017 Jul;7(1):4597.

3 Quan J, Zhang R, Liang H, Li F, Liu H. The clinicopathologic and prognostic analysis of adenosquamous and squamous cell carcinoma of the stomach. Am Surg. 2013 May;79(5):E206-8.

4 Rolleston H, Trevor RS. A case of columnar-celled carcinoma of the stomach showing squamous-celled metaplasia. J Pathol Bacteriol. 1905;10(4):418-22.

5 Kim YS, Heo WS, Chae KH, Gang YS, Jung JH, Kim SH, et al. [Clinicopathological features and differences of p53 and Ki-67 expression in adenosquamous and squamous cell carcinomas of the stomach]. Korean J Gastroenterol. 2006 Jun;47(6):425-31.

6 Samejima Y, Mizuno T, Sasakawa M, Takemura H, Watanabe A, Nagamatsu M. [A case report of early gastric adenoacanthoma and brief review of its literature]. I To Cho. 1974;9:783-88. Japanese.

7 Hirai S, Koyama S, Ebihara T, Nakahara A, Yamagata S, Muto H, et al. [Two cases of the gastric adenosquamous cell carcinoma diagnosed by gastroscopic biopsy]. J Gastroenterol Endosc. 1986 Jan;28(12):3139-45. Japanese.

8 Johzaki H, Murayama H, Maekawa T, Kikuchi M, Satoh M. [A case of small squamous cell carcinoma with a grading of IIa + IIc, an early gastric cancer type]. Gan No Rinsho. 1988 Jul;34(8):1025-30. Japanese.

9 Yoshida K, Manabe T, Tsunoda T, Kimoto M, Tadaoka Y, Shimizu M. Early gastric cancer of adenosquamous carcinoma type: report of a case and review of literature. Jpn J Clin Oncol. 1996 Aug;26(4):252-7.

10 Kimura Y, Matsuda H, Saeki H, Oki E, Morita M, Sugimachi K, et al. Case of early adenosquamous carcinoma of the stomach. Fukuoka Igaku Zasshi. 2013 Sep;104(9):315-20.

11 Jung CW, Choi JW, Kim BJ, Park SK, Park HU. A Case of Early Gastric Cancer of Adenosquamous Carcinoma. Korean J Helicobacter Up Gastrointest Res. 2014;14(3):207-10.

12 Shirahige A, Suzuki H, Oda I, Sekiguchi M, Mori G, Abe S, et al. Fatal submucosal invasive gastric adenosquamous carcinoma detected at surveillance after gastric endoscopic submucosal dissection. World J Gastroenterol. 2015 Apr;21(14):4385-90.

13 Saito S, Hosoya Y, Morishima K, Ui T, Haruta H, Kurashina K, et al. A clinicopathological and immunohistochemical study of gastric cancer with squamous cell carcinoma components: a clinically aggressive tumor. J Dig Dis. 2012 Aug;13(8):407-13. 

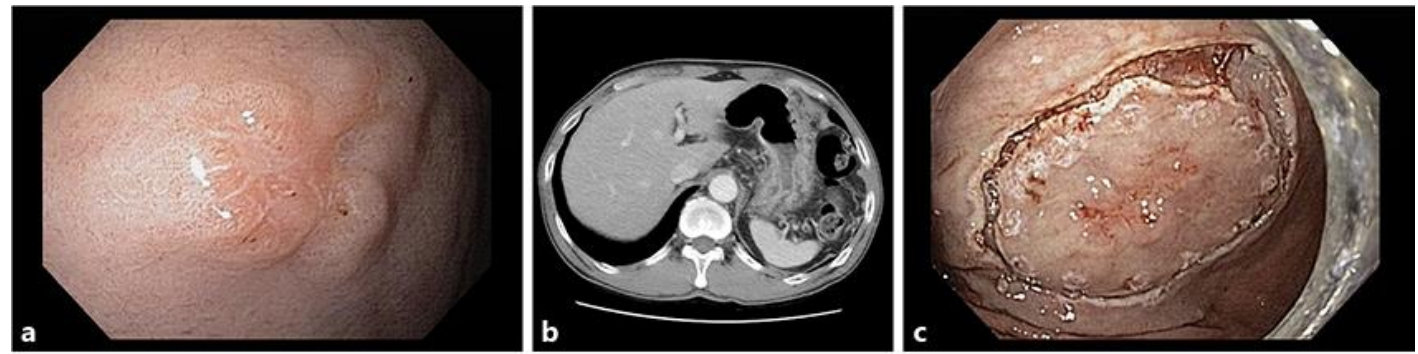

Fig. 1. a Esophagogastroduodenoscopy shows a superficial mucosal ulcerative lesion suspicious of type 0IIc early gastric cancer in the anterior wall of the distal body of the stomach. $\mathbf{b}$ Abdominal computed tomography scan indicates no definite mass or wall thickening of the stomach and revealed neither lymph node enlargement nor distant metastasis. c Endoscopic submucosal dissection was performed. 


\section{Case Reports in Gastroenterology}

Case Rep Gastroenterol 2019;13:165-172

\begin{tabular}{l|l} 
DOI: $10.1159 / 000499447$ & c 2019 The Author(s). Published by S. Karger AG, Basel
\end{tabular} www.karger.com/crg

Bae and Seo: Early Gastric Adenosquamous Carcinoma Resected Using Endoscopic Submucosal Dissection
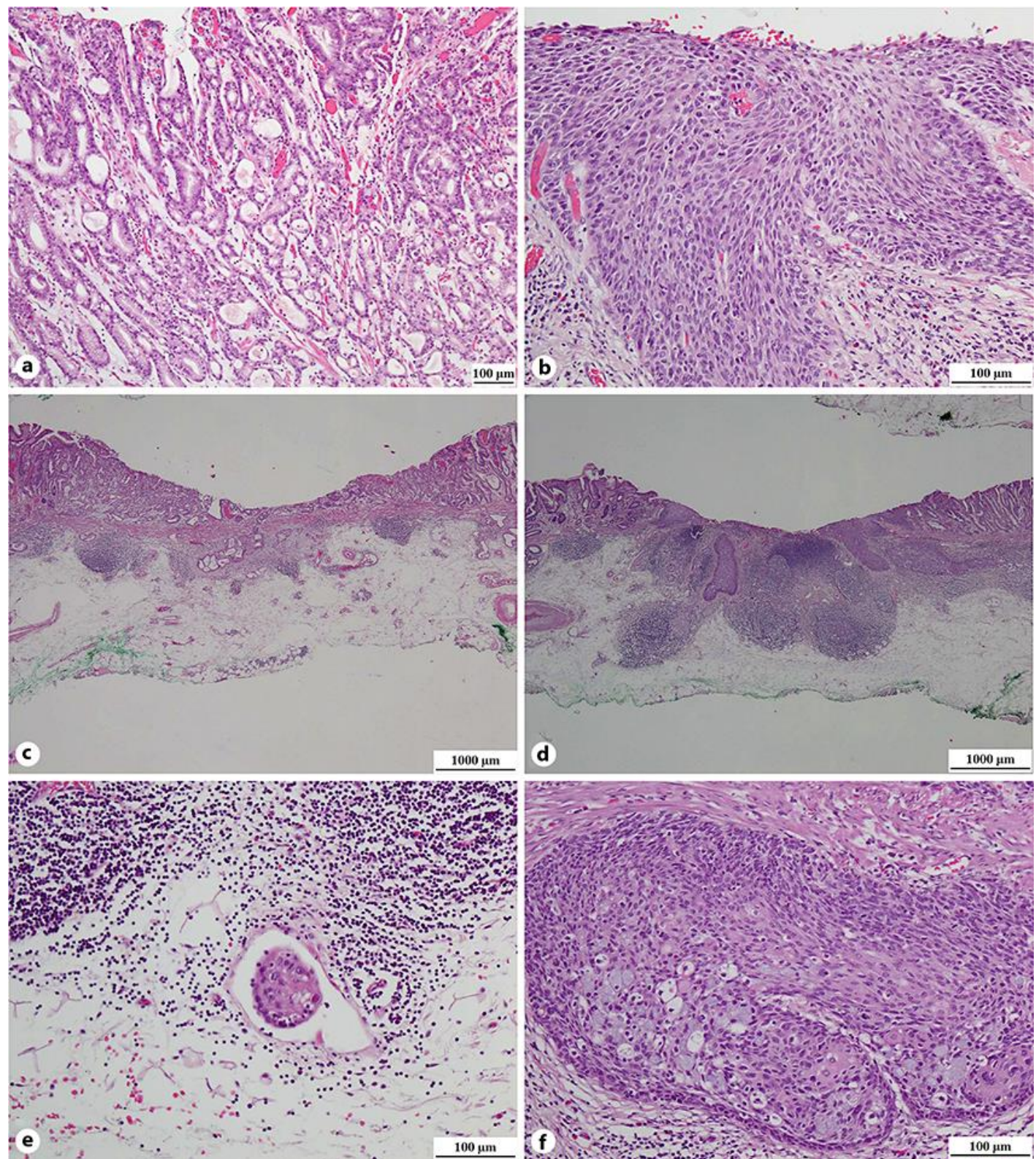

Fig. 2. Representative histopathologic findings of endoscopic submucosal dissection specimen (HE). a Tubular moderately differentiated adenocarcinoma was observed $(\times 100)$. b Squamous cell carcinoma (SqCC) with an intercellular bridge was found $(\times 200)$. c, $d$ Two individual carcinoma components invaded into the submucosal layer $(\times 20)$. e Lymphovascular invasion was found $(\times 400)$. $f$ Few cells with mucin production were infrequently shown in the SqCC components $(\times 400)$. 


\section{Case Reports in \\ Gastroenterology}

\begin{tabular}{l|l}
\hline Case Rep Gastroenterol 2019;13:165-172 \\
\hline DOI: 10.1159/000499447 & $\begin{array}{l}\text { ○ 2019 The Author(s). Published by S. Karger AG, Basel } \\
\text { www.karger.com/crg }\end{array}$ \\
\hline
\end{tabular}

Bae and Seo: Early Gastric Adenosquamous Carcinoma Resected Using Endoscopic Submucosal Dissection

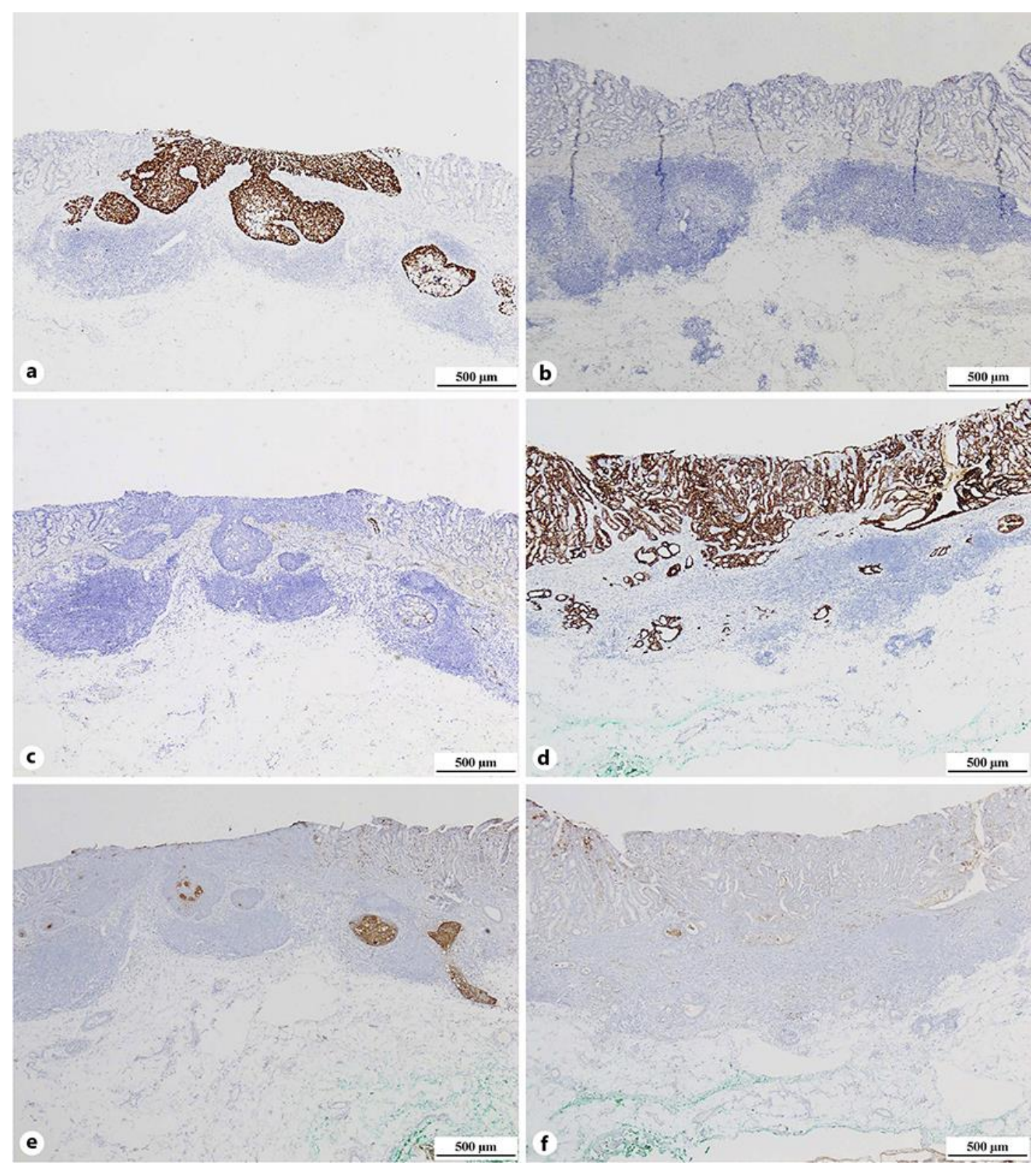

Fig. 3. Representative imaging of Immunohistochemistry (IHC). IHC for p40 was strongly expressed in squamous cell carcinoma (SqCC) components (a) but not in adenocarcinoma components (b). In contrast, CK7 showed no expression in SqCC components (c) and positivity in adenocarcinoma components (d). CEA was positively expressed in some areas of both SqCC (e) and adenocarcinoma components (f) (all ×40). 